\title{
Lysosomal membrane permeabilization causes secretion of IL-1 $\beta$ in human vascular smooth muscle cells
}

\author{
Hiroaki Ono ${ }^{1,2} \cdot$ Ryo Ohta $^{1} \cdot$ Yuri Kawasaki ${ }^{1} \cdot$ Akira Niwa $^{1} \cdot$ Hidetoshi Takada $^{3,4} \cdot$ Tatsutoshi Nakahata $^{1}$. \\ Shouichi Ohga ${ }^{2} \cdot$ Megumu K. Saito $^{1}$ (])
}

Received: 21 February 2018 / Revised: 1 August 2018 / Accepted: 3 August 2018 / Published online: 22 August 2018

(c) The Author(s) 2018

\begin{abstract}
Objective IL-1 $\beta$ secretion by the inflammasome is strictly controlled and requires two sequential signals: a priming signal and an activating signal. Lysosomal membrane permeabilization (LMP) plays a critical role in the regulation of NLRP3 inflammasome, and generally acts as an activating signal. However, the role of LMP controlling NLRP3 inflammasome activation in human vascular smooth muscle cells (hVSMCs) is not well defined.

Methods LMP was induced in hVSMCs by Leu-Leu- $O$-methyl ester. Cathepsin B was inhibited by CA-074 Me. Cytokine release, mRNA, and protein were quantified by enzyme-linked immunosorbent assay, quantitative PCR, and Western blot, respectively. NF- $\kappa \mathrm{B}$ activity was analyzed by immunostaining of the NF- $\kappa \mathrm{B}$ p65 nuclear translocation and using the dualluciferase reporter assay system.

Results LMP had both priming and activating roles, causing an upregulation of proIL-1 $\beta$ and NLRP3 and the secretion of mature IL-1 $\beta$ from unprimed hVSMCs. LMP activated the canonical NF- $\kappa$ B pathway. The priming effect of LMP was inhibited by CA-074 Me, indicating an upstream role of cathepsin B.

Conclusions These data support a novel role of LMP as a single stimulus for the secretion of IL- $1 \beta$ from hVSMCs, implying the possibility that hVSMCs are an important initiator of the sterile inflammatory response caused by lysosomal disintegration.
\end{abstract}

Keywords Inflammasome $\cdot$ Lysosomal membrane permeabilization (LMP) $\cdot$ Human vascular smooth muscle cells (hVSMCs) $\cdot \mathrm{NF}-\kappa \mathrm{B} \cdot$ Cathepsin B

\section{Abbreviations}

PRP Pattern recognition receptors

ASC Apoptosis-associated speck-like protein

ROS Reactive oxygen species

LMP Lysosomal membrane permeabilization

Responsible Editor: Yoshiya Tanaka.

Megumu K. Saito

msaito@cira.kyoto-u.ac.jp

1 Department of Clinical Application, Center for iPS Cell Research and Application, Kyoto University, Kyoto 606-8507, Japan

2 Department of Pediatrics, Graduate School of Medical Sciences, Kyushu University, Fukuoka 812-8582, Japan

3 Department of Perinatal and Pediatric Medicine, Graduate School of Medical Sciences, Kyushu University, Fukuoka 812-8582, Japan

4 Department of Child Health, Faculty of Medicine, University of Tsukuba, Ibaraki 305-8575, Japan
hVSMC Human vascular smooth muscle cell

HASMC Human aortic smooth muscle cell

HCASMC Human coronary artery smooth muscle cell

HPASMC Human pulmonary artery smooth muscle cell

LLME Leu-Leu- $O$-methyl ester

YVAD Ac-Tyr-Val-Ala-Asp-CHO

DPI Diphenyliodonium chloride

ML Monocytic cell lines

qPCR Quantitative polymerase chain reaction

CTSB Cathepsin B

\section{Introduction}

Inflammation is a host response caused by the immune system against harmful stimulation. The inflammatory response should be tightly regulated, because an excessive inflammatory response can cause systemic inflammatory disease, while a poor inflammatory response can lead to a persistent or fatal infection of pathogens. The inflammasome is one 
of the most critical machineries for regulating the innate immune response. It initiates a proinflammatory response by recognizing damage-associated and pathogen-associated molecular patterns on its pattern recognition receptors (PRPs) [1]. The inflammasome is subcategorized according to the PRPs incorporated, and among them, the NLRP3 inflammasome is one of the most investigated for its involvement in various inflammatory disorders and conditions [2].

The NLRP3 inflammasome is a protein complex involved in the secretion of proinflammatory cytokines interleukin (IL) $-1 \beta$ and IL-18, and is typically composed of a PRP NLRP3, apoptosis-associated speck-like protein (ASC), and a protease caspase- 1 . The secretion of IL- $1 \beta$ requires two sequential signals: a priming signal and an activating signal [3]. The first priming signal, which is evoked by LPS and TNF $\alpha$, primes the cells to upregulate the immature form of IL-1 $\beta$ (pro IL-1 $\beta$ ) and some inflammasome components. Then, the secondary activating signal acts on the primed cell to assemble the inflammasome complex. For the NLRP3 inflammasome, there are a number of identified activating signals, such as extracellular ATP, potassium efflux, intracellular reactive oxygen species (ROS), and increased lysosomal membrane permeabilization (LMP). Activation of the NLRP3 inflammasome causes auto-cleavage of the pro-form of caspase- 1 , and the resulting activated caspase- 1 then converts pro IL- $1 \beta$ into mature active IL- $1 \beta[4,5]$. Activation of the NLRP 3 inflammasome also causes programmed cell death by pyroptosis or pyronecrosis. This two-step mechanism tightly controls the secretion of IL- $1 \beta$ and the activation of the NLRP3 inflammasome. Currently, there is no known cell type that secretes mature IL- $1 \beta$ with a single stimulation, except for human monocytes, which can produce mature IL- $1 \beta$ with a single LPS stimulation $[6,7]$.

Vascular smooth muscle cells (VSMCs) compose the majority of blood vessel walls at the vascular media, which locates at the outer layer of vascular endothelial cells. The main function of VSMCs is to adjust the diameter of the blood vessels in response to stimuli. The vascular media can also be the site of sterile inflammation, because immune cells infiltrate there [8]. Especially in the case of atherosclerosis, chronic inflammation is evoked by infiltrating macrophages that are activated by cholesterol crystals and oxidized lowdensity lipoproteins [9]. Since cholesterol crystals act as an activating signal for the NLRP3 inflammasome, activated macrophages produce large amounts of IL- $1 \beta$ while infiltrating the media $[9,10]$. Interestingly, some human VSMCs (hVSMCs) express components of the NLRP3 inflammasome at the site of atherosclerosis, and hVSMCs themselves can contribute to local inflammation [11]. However, the role of hVSMCs on inflammasome-mediated vascular inflammation has not been fully elucidated.

Here, we found that a single signal, LMP, is enough to secrete IL-1 $\beta$ from unprimed hVSMCs. LMP is known as an important activating signal for the NLRP3 inflammasome, because activation of the NLPR3 inflammasome in various chronic inflammatory disorders, such as gout, atherosclerosis, and diabetes mellitus, takes place as a consequence of lysosomal disintegration [12]. On the other hand, in hVSMCs, in vitro experiments indicate that LMP can be both the priming and activating signal, making it sufficient for mature IL-1 $\beta$ secretion. These data highlight previously unknown roles in the inflammatory response by hVSMCs and provide insights into the pathophysiology of chronic vascular inflammation.

\section{Materials and methods}

\section{Materials}

Human aortic smooth muscle cells (HASMCs, C0075C), human coronary artery smooth muscle cells (HCASMCs, C0175C), and human pulmonary artery smooth muscle cells (HPASMCs, C0095C) were purchased from Thermo Fisher Scientific (Waltham, MA). Leu-Leu- $O$-methyl ester (LLME, L7393), L-3-trans-(propylcarbamyl)oxirane-2-carbonylL-isoleucyl-Lf-proline methyl ester (CA-074 Me, C5732), and ATP (A2383) were purchased from Sigma-Aldrich (St. Louis, MO). Caspase-1 inhibitor Ac-Tyr-Val-Ala-Asp-CHO (YVAD, 400010) was purchased from Merck (Darmstadt, Germany). Diphenyliodonium chloride (DPI, D2356) was purchased from Tokyo Chemical Industry (Tokyo, Japan). MG132 (1748) was purchased from R\&D Systems (Minneapolis, MN). LPS from Escherichia coli K12 (tlrl-peklps) and MCC950 (inh-mcc) were purchased from InvivoGen (San Diego, CA). Nigericin (145-07263) and ionomycin (091-05833) were purchased from Wako Pure Chemical Industries (Osaka, Japan).

\section{Cell cultures}

HVSMCs (HASMCs, HCASMCs, and HPASMCs) were cultured in Smooth Muscle Cell Growth Medium-2 (CC3182; Lonza, Basel, Switzerland). Human pluripotent stem cell-derived immortalized monocytic cell lines (MLs) were cultured as previously described [13] in StemPro-34 serumfree medium (10639011; Thermo Fisher Scientific) containing $2 \mathrm{mM}$ of L-glutamine and $50 \mathrm{ng} / \mathrm{mL}$ of M-CSF (216-MC; R\&D Systems).

\section{Cytokine assays}

HVSMCs were seeded into 12-well plates (353043; Corning Incorporated, Corning, NY) and cultured until 100\% confluency. Cells were incubated with either $400 \mu \mathrm{L}$ of culture medium (negative control) or LLME for the indicated time periods. In some experiments, inhibitors (YVAD, MCC 950, $50 \mu \mathrm{M}$ of CA-074 Me, $20 \mu \mathrm{M}$ of DPI, or $10 \mu \mathrm{M}$ 
of MG132) were added $1 \mathrm{~h}$ prior to the LLME stimulation. To prepare primed HASMCs, cells were stimulated with $100 \mathrm{ng} / \mathrm{mL}$ TNF $\alpha$ for $24 \mathrm{~h}$. Primed or unprimed HASMCs were stimulated with $2.5 \mathrm{mM}$ LLME, $5 \mu \mathrm{M}$ ionomycin, or $1 \mu \mathrm{M}$ nigericin for $24 \mathrm{~h}$. MLs were stimulated with $1 \mu \mathrm{g} / \mathrm{mL}$ LPS for $24 \mathrm{~h}$ to prepare primed MLs. Primed or unprimed MLs adjusted to $1 \times 10^{6}$ cells $/ \mathrm{mL}$ were suspended in culture medium at the indicated concentration of LLME or $2.5 \mathrm{mM}$ ATP for the indicated time periods. The supernatants were collected after centrifugation at $10,000 \times \mathrm{g}$ for $5 \mathrm{~min}$ and stored at $-80{ }^{\circ} \mathrm{C}$ until assayed. Concentrations of cytokines were measured by LEGENDplex Multi-Analyte Flow Assay Kit (BioLegend, San Diego, CA) in accordance with the manufacturer's instructions. Quantification of the cytokines was done with a BD LSRII Flow Cytometer (BD Biosciences, San Jose, CA). For stimulation, cells were treated with reagents for the indicated time periods.

\section{FITC dextran imaging}

HASMCs were seeded onto multi-well glass-bottom dishes (D141400; Matsunami, Osaka, Japan), cultured with $0.5 \mathrm{mg} /$ $\mathrm{mL}$ of FITC dextran (F0918; Tokyo Chemical Industry) for $1 \mathrm{~h}$, and washed with PBS (-) twice. The cells were then incubated in culture medium with or without 2.5 mM LLME for 10 or $60 \mathrm{~min}$. The cells were visualized with a FluoVIew 10i confocal microscope (Olympus, Tokyo, Japan) and analyzed with ImageJ software (National Institutes of Health, Bethesda, MD).

\section{Immunostaining, NF-KB p65}

HASMCs were seeded onto multi-well glass-bottom dishes. The nuclear translocation of NF-kB p65 subunit was evaluated as previously described [14]. After culture for the indicated time periods, cells were fixed with $4 \%$ paraformaldehyde in PBS (-) for 30 min. Permeabilization and blocking were performed with blocking buffer [blocking One (02952, Nacalai Tesque, Kyoto, Japan) with $0.1 \%$ Tween20 (900564-5; Santa Cruz Biotechnology, Dallas, TX)] for $30 \mathrm{~min}$. Samples were then incubated with anti-NF- $\mathrm{BB}$ p65 rabbit mAb (8242S; Cell Signaling Technologies, Danvers, MA) in blocking buffer overnight at $4{ }^{\circ} \mathrm{C}$ and subsequently incubated with Alexa Fluor 488 goat anti-rabbit IgG (4412S; Cell Signaling Technologies) for $30 \mathrm{~min}$. The nuclei were stained with 49-6-diamidino-2-phenylindole dihydrochloride (DAPI, 32670; Sigma-Aldrich) in PBS (-). The cells were visualized with a FluoVIew10i confocal microscope and analyzed with ImageJ software.

\section{Immunoblotting}

Cell lysates were lysed in radioimmunoprecipitation buffer (188-02453; Wako Pure Chemical Industries) plus proteinase inhibitor cocktail (04080; Nacalai Tesque) and $1 \mu \mathrm{g} /$ $\mathrm{mL}$ of 2-Mercaptoethanol (21417; Nacalai Tesque). After centrifugation at $15,000 \times g$ for $10 \mathrm{~min}$ at $4{ }^{\circ} \mathrm{C}$, supernatants were collected. Culture supernatants were collected and concentrated by ultrafiltration using an Amicon Ultra device (UFC500324; Merck) with a $3 \mathrm{kDa}$ molecular weight cutoff. Samples were boiled in laemmli sample buffer (1610737; Bio-Rad, Hercules, CA) with $100 \mathrm{mM}$ dithiothreitol at $95^{\circ} \mathrm{C}$ for $5 \mathrm{~min}$. Proteins were then separated using SDS-PAGE and transferred to a polyvinylidene difluoride membrane. The membranes were blocked with PVDF Blocking Reagent for Can Get Signal (NKB101; Toyobo, Osaka, Japan) and immunoblotted using the following antibodies: mouse anti-NLRP3 (Cryo-2; AG-20B-0014-C100; Adipogen, San Diego, CA), rabbit anti-IL-1 3 (3866; Abcam, Cambridge, UK), rabbit anti-Caspase-1 (5125; Cell Signaling Technology), mouse anti-ASC (D086-3; Medical and Biological Laboratories, Nagoya, Japan), rabbit anti-IкB $\alpha$ (9242; Cell Signaling Technology), and HRP-conjugated rabbit anti- $\beta$ actin (5125; Cell Signaling Technology). The anti-IL-1 $\beta$ and anti-Caspase- 1 antibodies recognize both the pro and mature forms of the proteins. HRP-labeled horse anti-mouse (7076) and HRP-labeled goat anti-rabbit (7074) were purchased from Cell Signaling Technology and used as secondary antibodies. Immunoreactive bands were visualized using SuperSignal Western Blot Enhancer (46640; Thermo Fisher) and detected with LAS4000 (Fujifilm, Tokyo, Japan).

\section{Cell viability assay}

Cell number and viability were measured with a Countess Automated Cell Counter (Invitrogen, Carlsbad, CA).

\section{Quantitative PCR}

RNA samples were prepared from the cells with RNeasy Mini Kit (74106; Qiagen, Hilden, Germany). RNA was then subjected to reverse transcription with PrimeScript RT Master Mix (RR036B; Takara Bio Inc, Otsu, Japan). All procedures were performed in accordance with the manufacturer's instructions. Quantitative Polymerase chain reaction (qPCR) was performed on the Step One Plus Real-Time PCR System (Applied Biosystems, Foster City, CA). cDNA was subjected to qPCR, and SYBR Premix ExTaqII (RR390B; Takara Bio Inc) was used for the detection. Data were processed according to the $\Delta \Delta$ cycle threshold method, and the relative quantities are shown. Forward and reverse primers were as follows: (1) NLRP3: 5'-ATGTGGGGGAGAATGCCTTG-3', 5'-TTG 


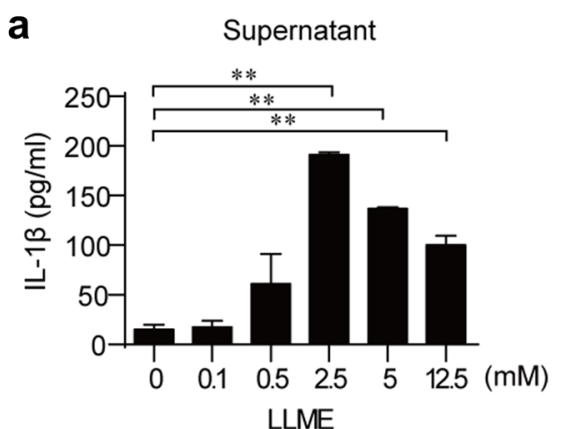

b
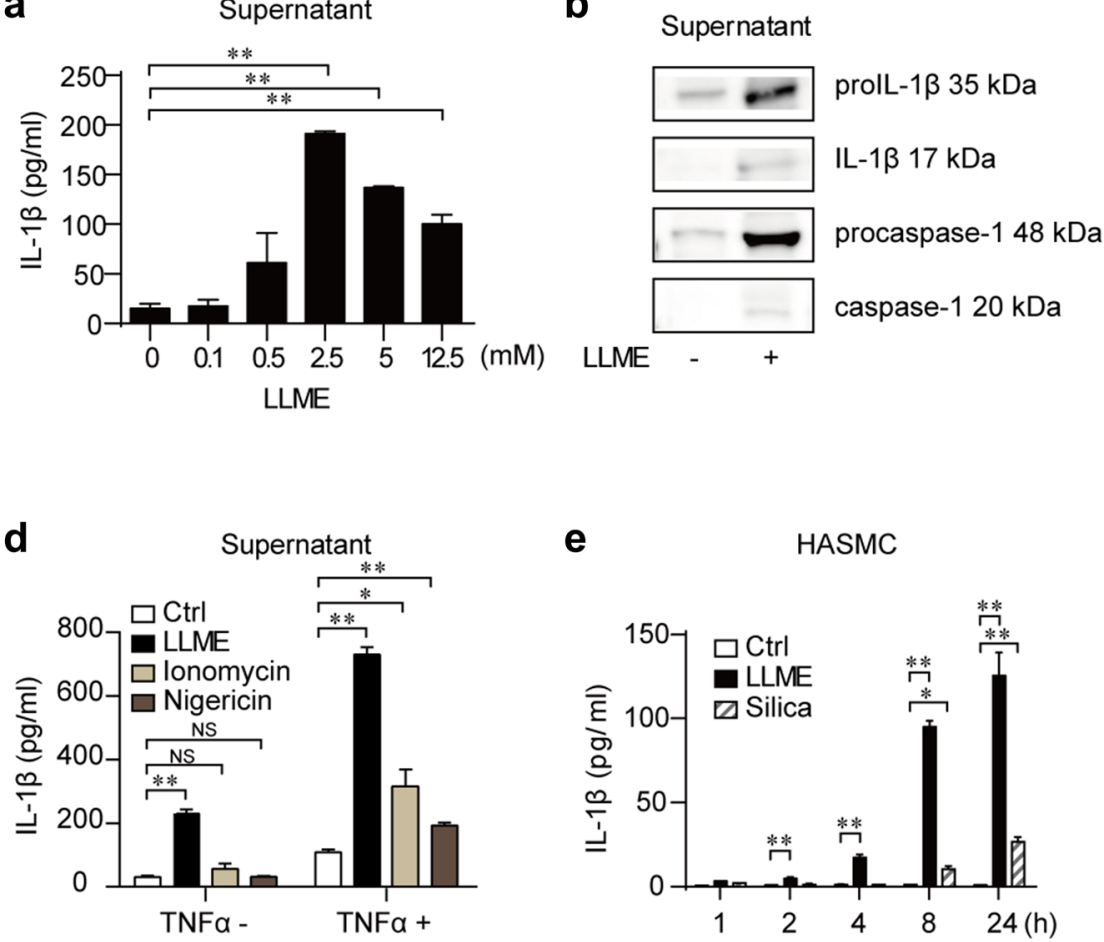

g

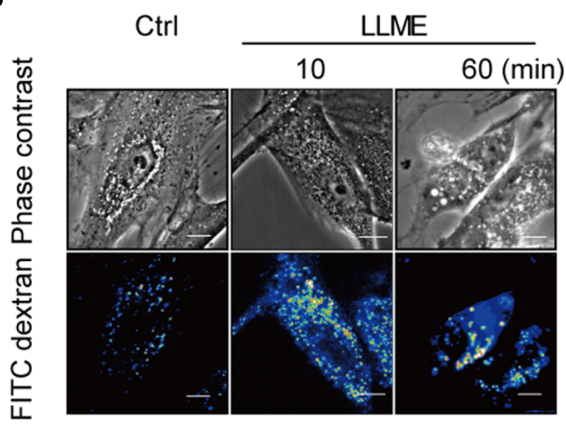

e

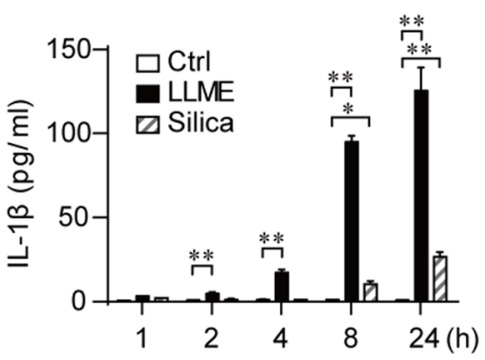

h

HASMC

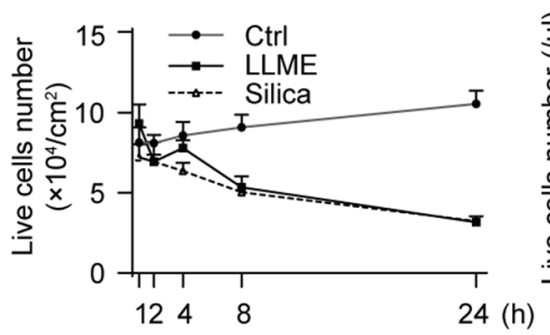

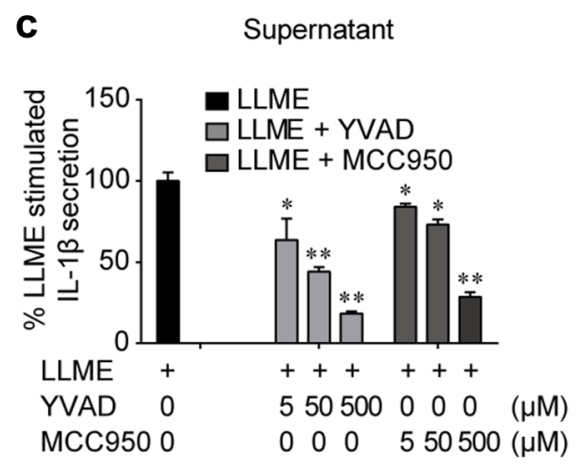

f

Supernatant

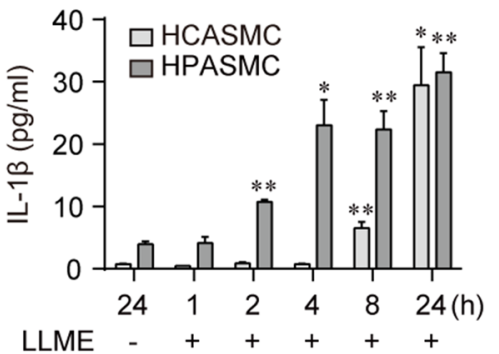

i

$\mathrm{ML}$

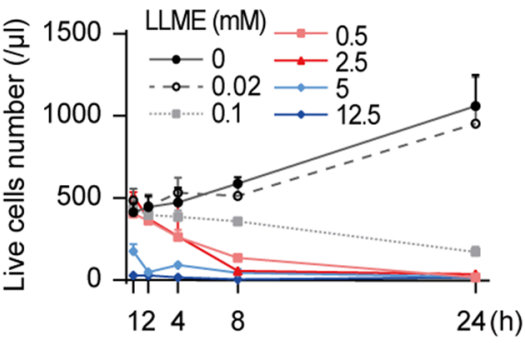

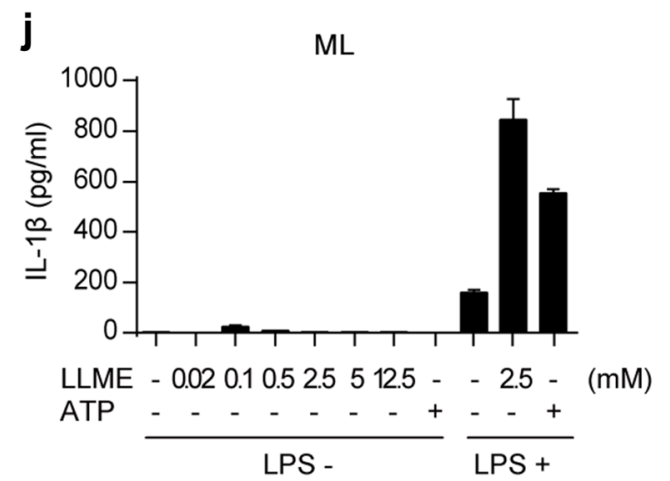

TCTCCGAGAGTGTTGCC-3'; (2) ILIB: 5'-TCGCCA GTGAAATGATGGCT-3', 5'-TGAAGCCCTTGCTGT AGTGG-3'; and (3) $\beta$-actin: 5'-ACAGAGCCTCGCCTT TGC-3', 5'-CCACCATCACGCCCTGG-3'.

\section{NF-KB dual-luciferase assay}

HASMCs were transfected with pGreenFire NF- $\mathrm{BB}$ transcription reporter lentivector (System Biosciences, Mountain View, CA) inserted with the Renilla gene under the 
४Fig. 1 Single LMP stimulation causes the secretion of mature IL-1 $\beta$ from unprimed human VSMCs. a HASMCs were treated with LLME $(0-12.5 \mathrm{mM})$, and the IL-1 $\beta$ concentrations were measured in the supernatant by LEGENDplex Multi-Analyte Flow Assay Kit after $24 \mathrm{~h}$ incubation. ${ }^{* *} p<0.005$ versus unstimulated cells. b Western blot of IL-1 $\beta$, pro-IL-1 $\beta$, caspase-1, and procaspase-1 in supernatant derived from HASMCs stimulated with LLME $(2.5 \mathrm{mM})$ for $24 \mathrm{~h}$. c IL-1 $\beta$ concentration in supernatant. HASMCs were cultured with increasing concentrations of YVAD or MCC950 and exposed to LLME (2.5 mM) for 24 h. $* p<0.05, * * p<0.005$ versus LLME-stimulated cells without YVAD $(5-500 \mu \mathrm{M})$, or MCC950 $(5-500 \mu \mathrm{M})$. d IL-1 $\beta$ concentration in supernatant. Unprimed or TNF $\alpha$-primed HASMCs were cultured with $2.5 \mathrm{mM}$ LLME, $5 \mu \mathrm{M}$ ionomycin, or $1 \mu \mathrm{M}$ nigericin. ${ }^{*} p<0.05$, $*^{*} p<0.005$ versus unstimulated cells in unprimed, or TNF $\alpha$-primed HASMCs. e Time course of the level of IL- $1 \beta$ in supernatant from LLME $(2.5 \mathrm{mM})$ - or silica $(500 \mu \mathrm{g} / \mathrm{mL})$-stimulated HASMCs. f Time course of the level of IL- $1 \beta$ in supernatant from HCASMCs and HPASMCs stimulated with LLME $(2.5 \mathrm{mM}) .{ }^{*} p<0.05, * * p<0.005$ versus unstimulated cells. $\mathbf{g}$ LMP detection by FITC dextran in cell culture. HASMCs were stained for $1 \mathrm{~h}$ with FITC dextran $(0.5 \mathrm{mg} / \mathrm{mL})$ and then stimulated with LLME $(2.5 \mathrm{mM})$ for 10 or $60 \mathrm{~min}$. Note the swelling and bursting of the punctate after LLME stimulation (FITC dextran staining). Scale bar: $10 \mu \mathrm{m}$. $\mathbf{h}$ Time course of the number of live HASMCs stimulated with LLME $(2.5 \mathrm{mM})$ or silica $(500 \mu \mathrm{g} /$ $\mathrm{mL})$. $\mathbf{i}$ Time course of the number of live MLs stimulated with LLME $(0-12.5 \mathrm{mM})$. j IL-1 $\beta$ concentration in supernatant. Unprimed MLs were stimulated with LLME $(0-12.5 \mathrm{mM})$ or ATP $(2.5 \mathrm{mM})$ for $24 \mathrm{~h}$. LPS $(1 \mu \mathrm{g} / \mathrm{mL})$-primed MLs were stimulated with LLME $(2.5 \mathrm{mM})$ or ATP $(2.5 \mathrm{mM})$ for $4 \mathrm{~h}$. a, $\mathbf{c}-\mathbf{f}, \mathbf{h}-\mathbf{j}$ Results are given as mean \pm SEM $(n=3)$. Statistical significance was evaluated by Student's $t$ test

CMV promoter as an internal control [14]. The NF- $\mathrm{BB}$ activity was then measured using the Dual-Luciferase Reporter Assay System (Promega, Madison, WI).

\section{Measurement of the intracellular ROS}

To measure intracellular ROS, cells were incubated in medium with or without LLME for $1 \mathrm{~h}$. CellROX Deep Red Reagent (C10422; Thermo Fisher) was added for the last $30 \mathrm{~min}$ at $37^{\circ} \mathrm{C}$. Cells were then collected and washed three times with PBS containing DAPI and assayed using BD LSRII Flow Cytometer. The data were analyzed with FlowJo software (TreeStar, Ashland, OR). Dead cells (DAPI+ cells) and debris were excluded by gating in the software. The mean fluorescence intensity of CellROX in each sample was regarded as the amount of ROS.

\section{Results}

\section{Single LMP stimulation is enough to secrete mature IL-1 $\beta$ from unprimed $h$ VSMCs}

As a model of LMP, we stimulated cells with a commonly used reagent, LLME. LLME is taken up by lysosomes, where it is cut by dipeptide peptidase I and destabilizes the lysosomal membrane immediately thereafter $[15,16]$. To investigate the effect of LMP on hVSMCs, we first treated a hVSMC line (HASMC) in the presence of LLME and detected the secretion of IL- $1 \beta$ in the culture supernatant (Fig. 1a). The amount of secreted IL-1 $\beta$ peaked at $2.5 \mathrm{mM}$ LLME (Fig. 1a). The mature and premature forms of both IL- $1 \beta$ and caspase- 1 were detected in the culture supernatant (Fig. 1b), proving that mature IL-1 $\beta$ was produced and secreted. We confirmed that mature IL- $1 \beta$ was processed via inflammasome activation, because the amount of secreted IL-1 $\beta$ with LLME stimulation was significantly decreased in the presence of a caspase-1 inhibitor, YVAD, and a NLRP3 inflammasome inhibitor, MCC950 [17] (Fig. 1c). In contrast to LLME stimulation, IL-1 $\beta$ was not secreted when unprimed HASMCs were stimulated with well-known activation signals of the NLRP3 inflammasome such as ionomycin or nigericin [18, 19] (Fig. 1d). Both ionomycin and nigericin treatment caused IL- $1 \beta$ secretion from TNF $\alpha$-primed HASMCs, confirming those signals indeed act as activation signals on HASMCs (Fig. 1d). At $2.5 \mathrm{mM}$ LLME, the secretion of IL- $1 \beta$ increased over time (Fig. 1e). We tested another LMP stimulation, silica, which physically disrupts lysosomes $[20,21]$. The induced IL-1 $\beta$ secretion from HASMCs with silica showed a similar tendency to that with LLME stimulation, although the amount of secreted IL-1b was smaller (Fig. 1e). The IL- $1 \beta$ secretion by LLME stimulation was reproduced in other hVSMCs (HCASMC and HPASMC), although again the amount of IL-1 $\beta$ secretion was smaller than that from HASMCs (Fig. 1f).

\section{HVSMCs are relatively resistant to LMP-induced cell death}

Since LMP usually induces cell death [21], we next evaluated the cytotoxicity of LLME on HASMCs. At $2.5 \mathrm{mM}$, LLME treatment immediately caused lysosome swelling and bursting in HASMCs, indicating the occurrence of LMP (Fig. 1g) [22]. The number of live HASMCs decreased gradually after the administration of LLME or silica, but a substantial number of cells survived $24 \mathrm{~h}$ later nevertheless (Fig. 1h). HCASMCs and HPASMCs also survived at least partially after $24 \mathrm{~h}$ of LLME treatment (data not shown). To test the cytotoxicity of LLME on monocytic cells, we treated human pluripotent stem cell-derived monocytic cell lines (MLs) [13] with LLME at 2.5 mM. All MLs perished within $24 \mathrm{~h}$ (Fig. 1i), showing the effects of LLME-induced LMP differ with the cell type. MLs secreted little IL- $1 \beta$ in response to LLME treatment, while LPS priming resulted in robust IL-1 $\beta$ secretion upon secondary LLME or ATP stimulation (Fig. 1j) [13], confirming that LLME acts as an activating signal for monocytic cells. Since the MLs were more sensitive to LLME-induced cell death than HASMCs, we treated MLs with a lower dose of LLME to see whether 

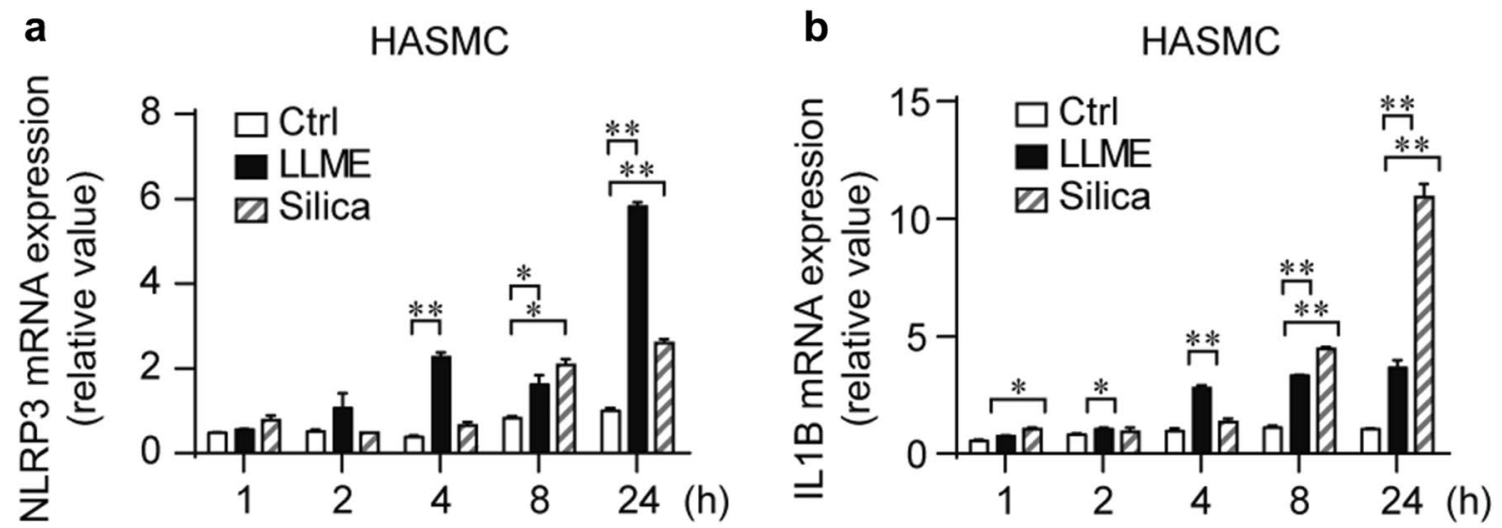

C

\section{Cell lysate}
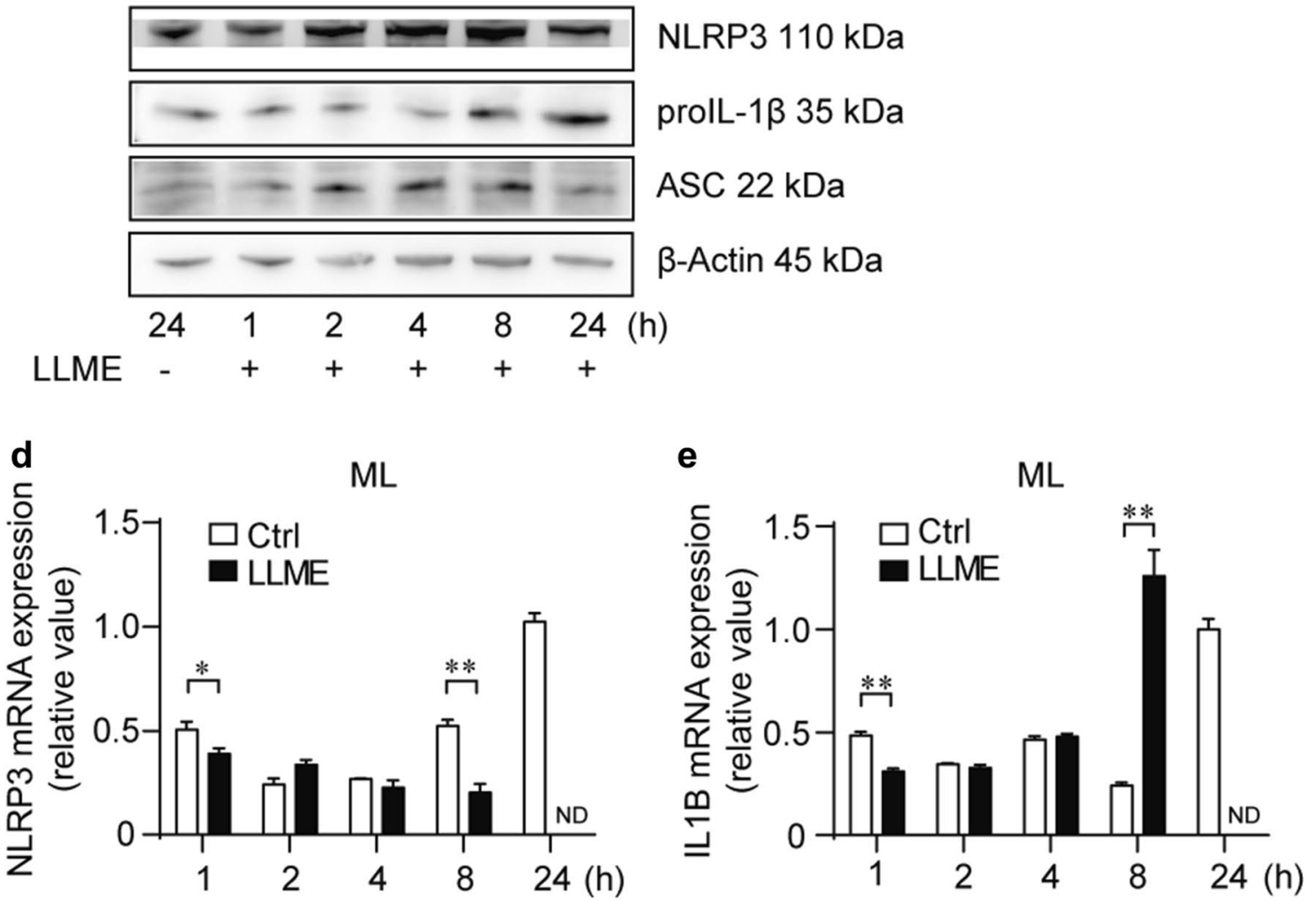

Fig. 2 LMP primes the NLRP3 inflammasome of HASMCs. a, b NLRP3 and IL1B mRNA expression in HASMCs stimulated with LLME $(2.5 \mathrm{mM})$ or silica $(500 \mu \mathrm{g} / \mathrm{mL})$ for $1-24 \mathrm{~h}$. Values are relative to unstimulated cells at $24 \mathrm{~h}$. c Western blot of NLRP3, pro-IL-1 $\beta$, ASC, and $\beta$-actin in cell lysate derived from HASMCs stimulated with LLME $(2.5 \mathrm{mM})$ for the indicated times. $\beta$-Actin was re-blotted from the stripped membrane for NLRP3 and proIL- $\beta$. The blot of ASC was

mild LMP with lower cytotoxicity can prime the MLs (Fig. 1i). Although 0.1 or $0.02 \mathrm{mM}$ LMP caused lower ML cytotoxicity, the amount of IL-1 $\beta$ secreted from these cells was negligible when compared with the LPS-primed condition (Fig. 1j). These data support our hypothesis that LMP

derived from the same samples. d, e NLRP3 and IL-1 $\beta$ mRNA expression in MLs stimulated with LLME (2.5 mM) for 1-24 h. All MLs stimulated with LLME were dead at $24 \mathrm{~h}$. Results are given as means \pm SEM $(n=3) . * p<0.05, * * p<0.005$ versus control cells at each time period, statistical significance was evaluated by Student's $t$ test

has cell-type-specific effects on IL- $1 \beta$ secretion. Overall, LMP caused the secretion of mature IL- $1 \beta$ from unprimed hVSMCs, suggesting that LMP has both priming and activating roles on the inflammasome in unprimed hVSMCs, but not in unprimed monocytic cells in which LLME has a role 
Fig. 3 LLME treatment activates the canonical NF- $\mathrm{\kappa B}$ pathway in HASMCs. a NF- $\kappa \mathrm{B}$ activation was evaluated using an NF- $\mathrm{KB}$ luciferase reporter system. Cells were stimulated with or without $2.5 \mathrm{mM}$ LLME for the indicated times. The relative fold change from the unstimulated condition is shown. Results are given as mean $\pm \operatorname{SEM}(n=6) . * p<0.05$, $* * p<0.005$ versus unstimulated cells, Student's $t$ test. b Representative confocal images of immunofluorescence staining of NF-кB p65 (green). Cells were stimulated with LLME (2.5 mM) for 1 or $2 \mathrm{~h}$. Cells were stained with DAPI for visualization of the nucleus (white). Scale bars: $40 \mu \mathrm{m}$. c Quantitation of the nuclear translocation of NF- $\mathrm{KB}$ p65 by immunofluorescence staining.

The mean fluorescence intensity of NF- $\kappa B$ p65 merged with the nucleus in each cell is plotted. Bars indicate mean \pm SD $(n=143-231)$. Mann-Whitney $U$ test was used for the statistical analysis. $\mathbf{d}$ I $\kappa \mathrm{B} \alpha$ protein was analyzed after 0-60 min LLME stimulation. e IL- $1 \beta$ concentration in supernatant from LLMEstimulated HASMCs with MG132 (0-10 $\mu \mathrm{M})$. Results are given as mean $\pm \operatorname{SEM}(n=3)$. $* p<0.05, * * p<0.005$ versus LLME-stimulated cells without MG132, Student $t$ test. (Color figure online) a

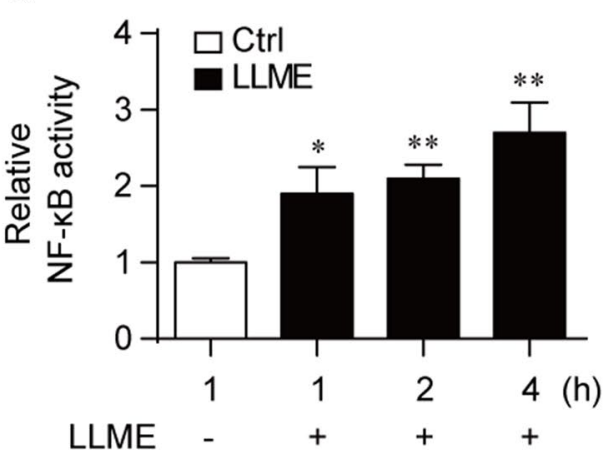

b

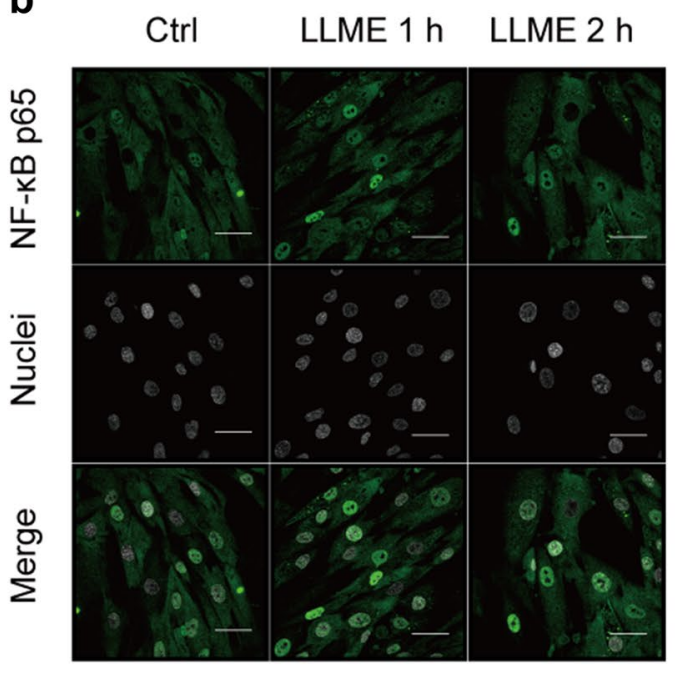

C

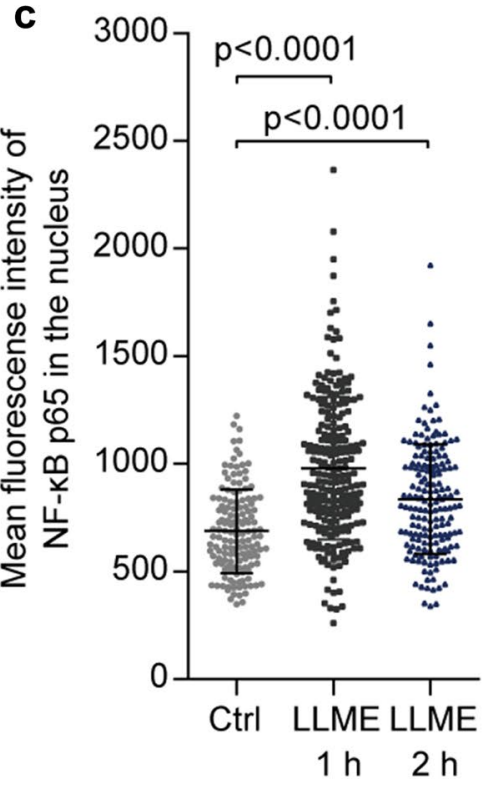

d

Cell lysate

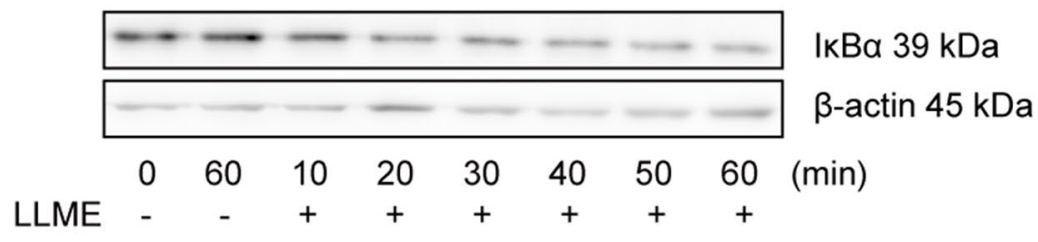


of inducing cell death. The different response in different cell types to LLME could explain the different survival rates and may be associated with LLME-induced IL- $1 \beta$ secretion in hVSMCs. Indeed, IL-1 $\beta$ secretion from LLME-treated HASMCs could be detected from $8 \mathrm{~h}$ after stimulation and increased with time (Fig. 1e).

\section{LLME-induced LMP primes the NLRP3 inflammasome of HASMCs}

To confirm the priming role of LLME on HASMCs, we next examined the expression of NLRP3 and proIL- $1 \beta$ after LLME stimulation. The time-dependent upregulation of NLRP3 and IL1B by LLME or silica stimulation was confirmed by mRNA levels (Fig. 2a, b). The upregulation of NLRP 3 and proIL-1 $\beta$ was also confirmed at the protein level (Fig. 2c), confirming the priming role of LLME on HASMCs. The upregulation of NLRP3 and IL1B at the mRNA level by LLME was not observed in MLs (Fig. 2d, e). Therefore, we concluded that LLME has no priming effect on monocytic cells, which is consistent with previous findings [12]. These data support a specific role of LMP on HASMCs for promoting the priming of the NLRP3 inflammasome, thereby evoking a proinflammatory response in these cells.

\section{LLME treatment activates canonical NF-KB pathway in HASMCs}

Priming of the NLRP3 inflammasome requires the activation of intracellular signaling cascades, with one of the most important being NF- $\mathrm{KB}$ signaling [1,23]. Genes involved in the inflammasome-IL-1 pathway, such as IL1B and NLRP3, are transcribed as a result of NF- $\kappa \mathrm{B}$ activation $[4,24]$. We hypothesized that in hVSMCs, LMP activates the NF- $\mathrm{B}$ pathway, leading the cells to be primed while escaping from death. Indeed, LLME treatment increased NF- $\kappa B$ reporter activity in HASMCs (Fig. 3a). In line with this finding, NF- $\kappa$ B p65 subunit translocated to the nucleus after LLME stimulation (Fig. 3b, c). Degradation of I $\mathrm{B} \alpha$, an essential step for the nuclear translocation of NF- $\mathrm{KB}$ p50/p65 subunits, was confirmed upon LLME stimulation (Fig. 3d). Furthermore, LLME-induced IL- $1 \beta$ secretion was inhibited by MG-132, an inhibitor of IкB $\alpha$ degradation (Fig. 3e), confirming that activation of the NF- $\mathrm{kB}$ pathway is an upstream event for IL-1 $\beta$ secretion. Overall, LLME treatment activates the canonical NF- $\kappa B$ pathway in HASMCs, and thus can act as a priming signal in these cells.

\section{Cathepsin B is involved in LMP-induced priming of HASMCs}

LMP causes the leakage of various lysosomal content such as reactive oxygen species (ROS), cathepsin, and hydrolases
Fig. 4 Cathepsin B is involved in LMP-induced priming of HASMCs. a ROS detection by CellROX in cell culture. HASMCs were stained with CellROX and stimulated with LLME $(2.5 \mathrm{mM})$ and DPI $(0-40 \mu \mathrm{M})$ for $1 \mathrm{~h}$. Results are given as means \pm SEM $(n=3)$. ** $p<0.005$ versus LLME-stimulated cells without DPI, Student's $t$ test. b, c IL-1 $\beta$ concentration in supernatant. HASMCs were cultured with increasing concentrations of DPI (B) or CA-074 Me and exposed to LLME $(2.5 \mathrm{mM})$ for $24 \mathrm{~h}$. Results are given as means \pm SEM $(n=3)$. $* p<0.05, * * p<0.005$ versus LLME-stimulated cells without DPI or CA-074 Me, Student $t$ test. d, e NLRP3 and IL1B mRNA expression in HASMCs stimulated with or without LLME $(2.5 \mathrm{mM})$ in the presence or absence of CA-074-Me $(50 \mu \mathrm{M})$, DPI $(20 \mu \mathrm{M})$ or MG132 $(10 \mu \mathrm{M})$. The relative fold change from unstimulated cells in each condition is shown. Results are given as mean \pm SEM $(n=3)$. $* p<0.05, * * p<0.005$ versus control cells, Student's $t$ test. f NF- $\kappa \mathrm{B}$ activation was evaluated using an NF- $\kappa \mathrm{B}$ luciferase reporter system. HASMCs were stimulated with LLME $(2.5 \mathrm{mM})$ in the presence or absence of CA-074-Me $(50 \mu \mathrm{M})$, DPI $(20 \mu \mathrm{M})$ and MG132 $(10 \mu \mathrm{M})$ for $2 \mathrm{~h}$. The relative fold change from the control cells is shown. Results are given as mean \pm SEM $(n=9)$. $* p<0.05,{ }^{*} p<0.005$ versus control cells, Student's $t$ test. g Evaluation of the nuclear translocation of NF- $\kappa B$ p65. Representative confocal images of the immunofluorescence staining of NF- $\mathrm{BB}$ p65 (green). Cells were treated with LLME $(2.5 \mathrm{mM})$ for $1 \mathrm{~h}$ in the presence or absence of CA-074-Me $(50 \mu \mathrm{M})$, DPI $(20 \mu \mathrm{M})$ and MG132 $(10 \mu \mathrm{M})$. Cells were stained with DAPI for visualization of the nucleus (white). Scale bar, $40 \mu \mathrm{m}$. $\mathbf{h}$ Quantitation of the nuclear translocation of NF- $\mathrm{kB}$ p65 by immunofluorescence staining. The mean fluorescence intensity of NF- $\mathrm{BB}$ p65 merged with the nucleus in each condition cell is plotted. Bars indicate means $\pm \mathrm{SD}(n=93-145)$. A Mann-Whitney $U$ test was used for the statistical analysis. i IкB $\alpha$ protein was analyzed after 0-60 $\min \operatorname{LLME}(2.5 \mathrm{mM})$ stimulation. HASMCs were pretreated with CA-074Me $(50 \mu \mathrm{M})$ for $1 \mathrm{~h}$. (Color figure online)

into the cytoplasm [21]. Since elevated cathepsin B (CTSB) and ROS in the cytoplasm are well-known activation signals of the NLRP3 inflammasome [5, 25], we next investigated their effect on HASMCs. Cytoplasmic ROS detected by CellROX increased upon treatment with LLME in HASMCs, but decreased with treatment of an NADPH oxidase inhibitor, DPI, in a dose-dependent manner (Fig. 4a). Furthermore, DPI treatment decreased LLME-induced IL-1 $\beta$ secretion from HASMCs (Fig. 4b). CA-074 Me, an inhibitor of CTSB, also decreased LLME-induced IL- $1 \beta$ secretion in a dose-dependent manner (Fig. 4c). To discriminate the priming and activating roles of these signals on IL- $1 \beta$ secretion, we next investigated whether ROS and CTSB contribute to the priming of HASMCs. Pretreatment of HASMCs with DPI had minimal effect on the LLME-induced upregulation of NLRP3 and IL1B, although we could not evaluate mRNA expression beyond $4 \mathrm{~h}$ due to the cytotoxicity of DPI (Fig. 4d, e). On the other hand, CA-074 Me almost completely inhibited the LLME-induced upregulation of these genes (Fig. 4d, e). In line with these findings, CA-074 Me inhibited the increased LLME-induced NF- $\mathrm{KB}$ reporter activity and nuclear translocation of NF- $\mathrm{KB}$ p65 subunit, while DPI failed to inhibit either event (Fig. 4f-h). However, interestingly, CA-074 Me did not inhibit IкB $\alpha$ degradation 

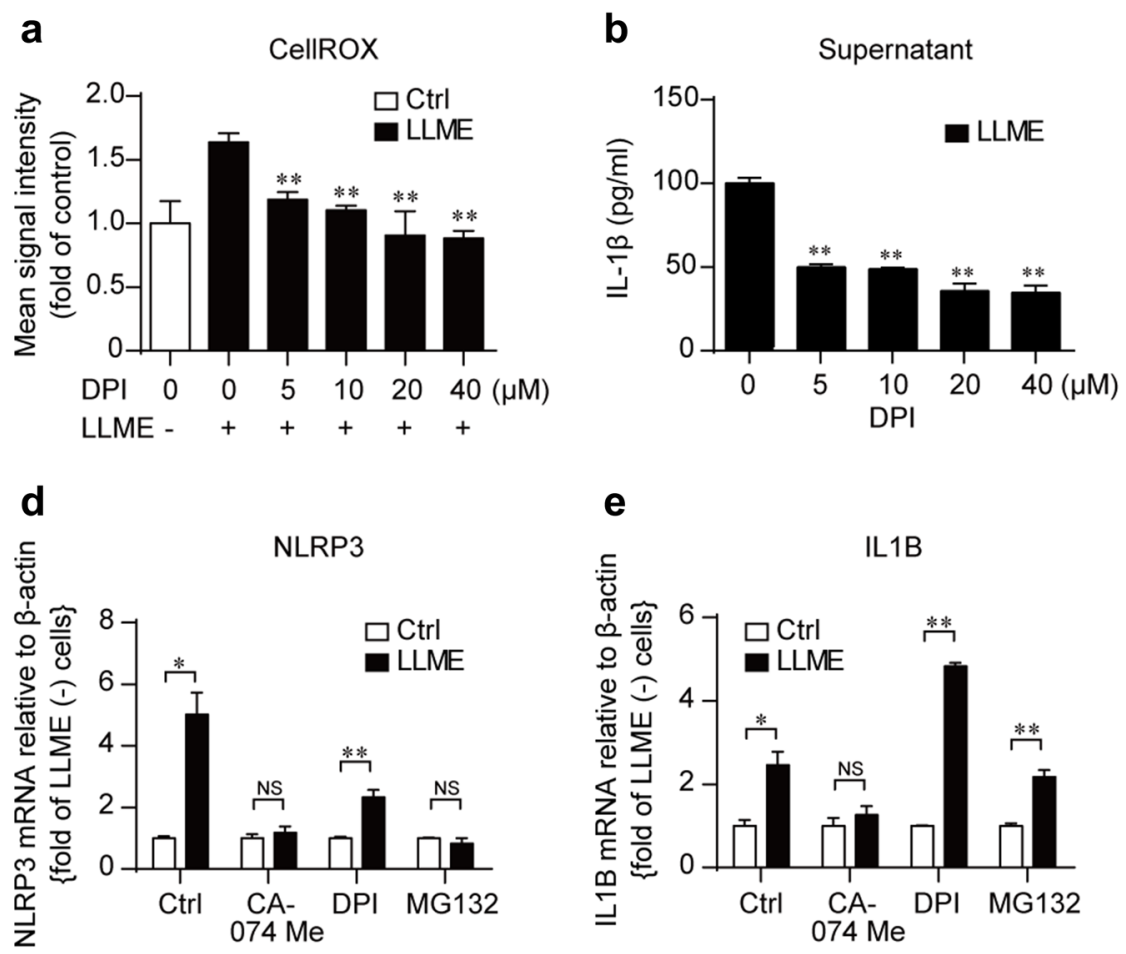

g

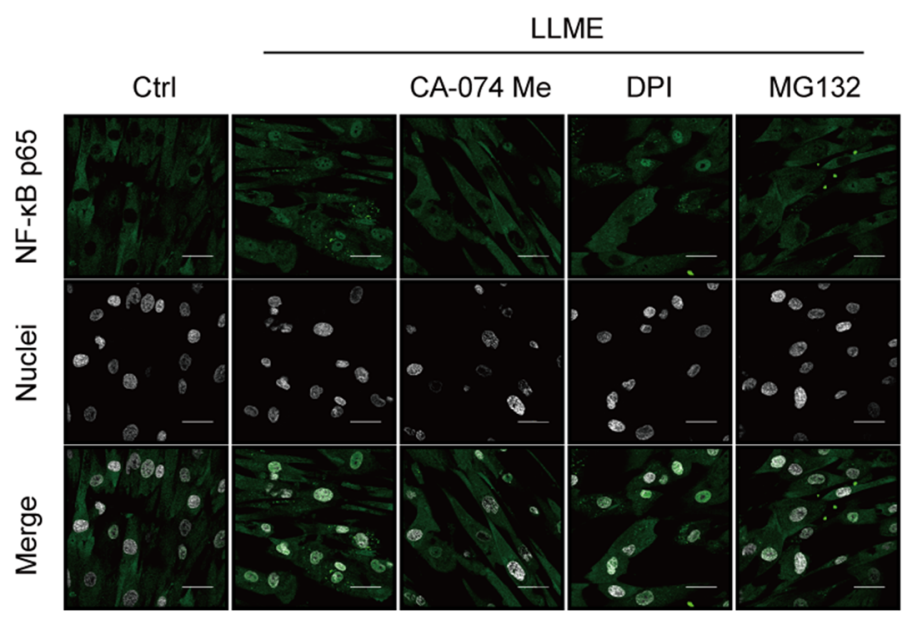

i

Cell lysate

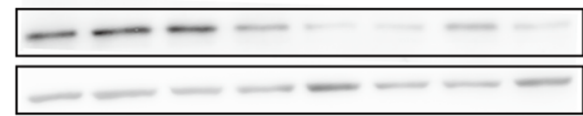

IkBa $39 \mathrm{kDa}$

$\beta$-actin $45 \mathrm{kDa}$

LLME

$\begin{array}{lllllllll}0 & 60 & 10 & 20 & 30 & 40 & 50 & 60 & \text { (min) }\end{array}$

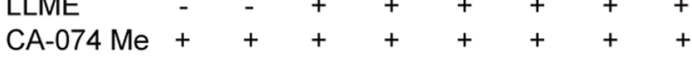

C

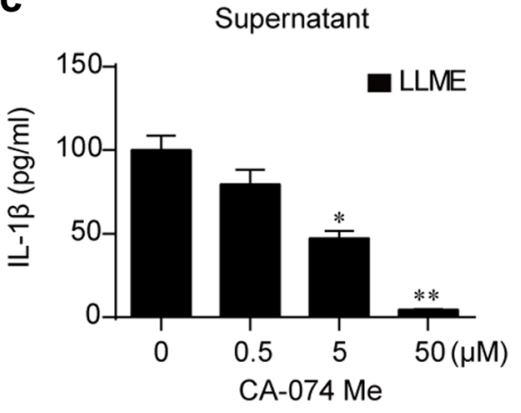

f

NF-KB

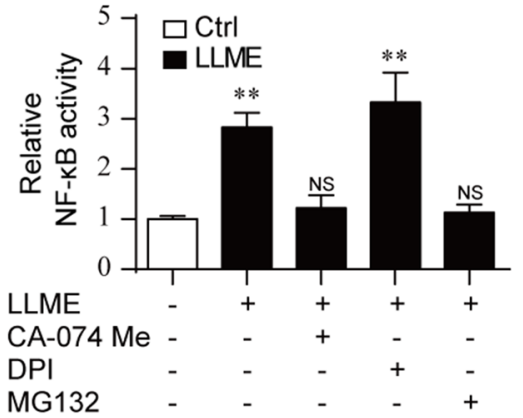

h

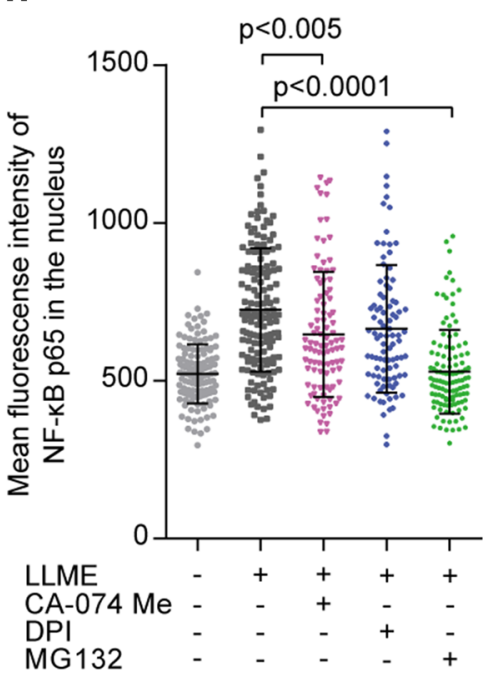


(Fig. 4i), indicating an additional role of CTSB on NF-kB activation beyond the degradation of IkBa. Overall, the priming effect of LLME on HASMCs is mediated by CSTB activity, at least in part, and intracellular ROS basically contributes as an activating signal.

\section{Discussion}

Here, we showed LMP is a sufficient signal for the secretion of IL-1 $\beta$ from hVSMCs. Oxidative low-density lipoproteins can induce LMP and enhance the production of IL- $1 \beta$ from HASMCs [26]. However, they also transduce intracellular signaling through the surface receptor CD36 [27, 28]. We, therefore, used LLME to induce LMP and found that LLME stimulation acts as a priming signal for hVSMCs along with its well-known role as an activating signal. These findings revealed a novel proinflammatory role of LMP on hVSMCs.

While the potential effects of alarmins, such as HMGB1 or IL- $1 \alpha$, on the priming vascular smooth muscle cells cannot be dismissed. However, we observed activation of the NF-kB signaling pathway immediately after the occurrence of LMP and the upregulation of IL1B/NLRP3 mRNA at $4 \mathrm{~h}$. Considering that most of the cells were still alive at these time points (Fig. 1h), the effects were likely negligible.

LMP stimulates cellular inflammation, but also cell death [21, 29]. Indeed, in our experiments, almost all MLs died after LLME treatment. However, HASMCs were relatively resistant to LLME-induced cell death, and the surviving cells upregulated IL1B and secreted IL- $1 \beta$ in a time-dependent manner. Inflammatory signals such as IL- $1 \beta$ enhance the migration and proliferation of VSMCs. For example, transgenic mice lacking functional IL-1 do not show neointimal hyperplasia, which is induced in wildtype mice by low levels of shear stress [30]. Inflammation, such as $\mathrm{NF}-\kappa \mathrm{B}$ activity and IL-1 secretion, regulates the proliferation of VSMCs $[13,31]$. Therefore, the proinflammatory response itself may be beneficial to hVSMCs for survival against fatal lysosomal disintegration. Activation of the NF- $\kappa \mathrm{B}$ pathway can also contribute to cell survival $[32,33]$.

Furthermore, our study revealed a previously unknown role of LMP to activate the canonical $N F-\kappa B$ pathway in HASMCs. The enzymatic activity of CTSB seems to be associated with this event, as its inhibition decreased both $\mathrm{NF}-\kappa \mathrm{B}$ activity and IL- $1 \beta$ secretion. In human and mouse hepatocytes, CTSB degrades sirtuin-1, thereby positively regulating the $\mathrm{NF}-\kappa \mathrm{B}$ pathway [34]. In macrophages, CTSB supports the translation of proIL-1 $\beta$ [35]. These studies indicate the positive relationship between CTSB activity and the proinflammatory response to inflammatory stimuli such as LPS or TNF $\alpha$. Interestingly, in murine macrophages, LLME induces the degradation of intracytoplasmic IL-1 $\beta$, contrary to our results [12]. Thus, the precise molecular mechanism that connects CTSB and $\mathrm{NF}-\kappa \mathrm{B}$ activation in HAMSCs remains to be elucidated.

Classically, the infiltration of hematopoietic cells initiates vascular inflammation. Activated monocytes and macrophages migrate into subintimal spaces and release various cytokines and chemokines including IL-1 $\beta$ [36, 37]. Consistent with this theory, most IL-1 $\beta$ expression is observed in macrophages and endothelial cells in the pathological specimen, but some VSMCs also express IL- $1 \beta$ $[11,37]$. In previous reports, the role of IL- $1 \beta$ in VSMCs has been relatively unattended. Our data support a novel role of LMP as a single stimulus for the secretion of IL-1 $\beta$ from hVSMCs even in the absence of innate immune cells. This characteristic feature of hVSMCs suggests that spontaneous inflammation occurs in vascular media before the infiltration of immune cells or the dysfunction of vascular endothelial cells. Further studies using in vivo models are required to validate this hypothesis. To conclude, hVSMCs may be an important initiator of the sterile inflammatory response caused by lysosomal disintegration.

Acknowledgements We thank Dr. Norikazu Saiki (CiRA, Kyoto University) for technical support, Dr. Toshiro Hara (Kyushu University) for useful advice and Ms. Harumi Watanabe (CiRA, Kyoto University) for administrative assistance. We also thank Dr. Peter Karagiannis (CiRA, Kyoto University) for editing and proofreading our manuscript. This work was supported by a grant from Japan Agency for Medical Research and Development (14525849) to HT, TN and MKS.

Author contributions $\mathrm{HO}$ performed almost all experiments. RO and YK performed experiments. HO, RO, YK, HT, and AN analyzed and interpreted the data. TN, SO, and MKS designed the study. HO and MKS wrote the manuscript. All of the authors read and edited the entire manuscript.

\section{Compliance with ethical standards}

Conflict of interest The authors have no financial conflicts of interest.

Open Access This article is distributed under the terms of the Creative Commons Attribution 4.0 International License (http://creativeco mmons.org/licenses/by/4.0/), which permits unrestricted use, distribution, and reproduction in any medium, provided you give appropriate credit to the original author(s) and the source, provide a link to the Creative Commons license, and indicate if changes were made.

\section{References}

1. Guo H, Callaway JB, Ting JP. Inflammasomes: mechanism of action, role in disease, and therapeutics. Nat Med. 2015;21(7):677-87. https://doi.org/10.1038/nm.3893.

2. Strowig T, Henao-Mejia J, Elinav E, Flavell R. Inflammasomes in health and disease. Nature. 2012;481(7381):278-86. https://doi. org/10.1038/nature10759. 
3. He Y, Hara H, Nunez G. Mechanism and regulation of NLRP3 inflammasome activation. Trends Biochem Sci. 2016;41(12):1012-21. https://doi.org/10.1016/j.tibs.2016.09.002.

4. Howard AD, Kostura MJ, Thornberry N, Ding GJ, Limjuco G, Weidner J, et al. IL-1-converting enzyme requires aspartic acid residues for processing of the IL-1 beta precursor at two distinct sites and does not cleave 31-kDa IL-1 alpha. J Immunol. 1991;147(9):2964-9.

5. Jo EK, Kim JK, Shin DM, Sasakawa C. Molecular mechanisms regulating NLRP3 inflammasome activation. Cell Mol Immunol. 2016;13(2):148-59. https://doi.org/10.1038/cmi.2015.95.

6. Elliott EI, Sutterwala FS. Monocytes take their own path to IL1beta. Immunity. 2016;44(4):713-5. https://doi.org/10.1016/j. immuni.2016.03.015.

7. Netea MG, Nold-Petry CA, Nold MF, Joosten LA, Opitz B, van der Meer JH, et al. Differential requirement for the activation of the inflammasome for processing and release of IL-1beta in monocytes and macrophages. Blood. 2009;113(10):2324-35. https:// doi.org/10.1182/blood-2008-03-146720.

8. Lim S, Park S. Role of vascular smooth muscle cell in the inflammation of atherosclerosis. BMB Rep. 2014;47(1):1-7.

9. Duewell P, Kono H, Rayner KJ, Sirois CM, Vladimer G, Bauernfeind FG, et al. NLRP3 inflammasomes are required for atherogenesis and activated by cholesterol crystals. Nature. 2010;464(7293):1357-61. https://doi.org/10.1038/nature08938.

10. Rajamaki K, Lappalainen J, Oorni K, Valimaki E, Matikainen S, Kovanen PT, et al. Cholesterol crystals activate the NLRP3 inflammasome in human macrophages: a novel link between cholesterol metabolism and inflammation. PloS One. 2010;5(7):e11765. https ://doi.org/10.1371/journal.pone.0011765.

11. Shi X, Xie WL, Kong WW, Chen D, Qu P. Expression of the NLRP3 inflammasome in carotid atherosclerosis. J Stroke Cerebrovasc Dis Off J Natl Stroke Assoc. 2015;24(11):2455-66. https ://doi.org/10.1016/j.jstrokecerebrovasdis.2015.03.024.

12. Lima H Jr, Jacobson LS, Goldberg MF, Chandran K, DiazGriffero F, Lisanti MP, et al. Role of lysosome rupture in controlling Nlrp3 signaling and necrotic cell death. Cell Cycle (Georget Tex). 2013;12(12):1868-78. https://doi.org/10.4161/cc.24903.

13. Haruta M, Tomita Y, Yuno A, Matsumura K, Ikeda T, Takamatsu $\mathrm{K}$, et al. TAP-deficient human iPS cell-derived myeloid cell lines as unlimited cell source for dendritic cell-like antigen-presenting cells. Gene Ther. 2013;20(5):504-13. https://doi.org/10.1038/gt.2012.59.

14. Takada S, Kambe N, Kawasaki Y, Niwa A, Honda-Ozaki F, Kobayashi $\mathrm{K}$, et al. Pluripotent stem cell models of Blau syndrome reveal an IFN-gamma-dependent inflammatory response in macrophages. J Allergy Clin Immunol. 2017. https://doi.org/10.1016/j. jaci.2017.04.013.

15. Thiele DL, Lipsky PE. Mechanism of L-leucyl-L-leucine methyl ester-mediated killing of cytotoxic lymphocytes: dependence on a lysosomal thiol protease, dipeptidyl peptidase I, that is enriched in these cells. Proc Natl Acad Sci USA. 1990;87(1):83-7.

16. Thiele DL, Lipsky PE. Apoptosis is induced in cells with cytolytic potential by L-leucyl-L-leucine methyl ester. J Immunol. 1992;148(12):3950-7.

17. Coll RC, Robertson AA, Chae JJ, Higgins SC, Munoz-Planillo $\mathrm{R}$, Inserra MC, et al. A small-molecule inhibitor of the NLRP3 inflammasome for the treatment of inflammatory diseases. Nat Med. 2015;21(3):248-55. https://doi.org/10.1038/nm.3806.

18. Katsnelson MA, Rucker LG, Russo HM, Dubyak GR. $\mathrm{K}^{+}$efflux agonists induce NLRP3 inflammasome activation independently of $\mathrm{Ca}^{2+}$ signaling. J Immunol. 2015;194(8):3937-52. https://doi. org/10.4049/jimmunol.1402658.

19. Murakami T, Ockinger J, Yu J, Byles V, McColl A, Hofer $\mathrm{AM}$, et al. Critical role for calcium mobilization in activation of the NLRP3 inflammasome. Proc Natl Acad Sci USA. 2012;109(28):11282-7. https://doi.org/10.1073/pnas.1117765109.
20. Thibodeau MS, Giardina C, Knecht DA, Helble J, Hubbard AK. Silica-induced apoptosis in mouse alveolar macrophages is initiated by lysosomal enzyme activity. Toxicol Sci Off J Soc Toxicol. 2004;80(1):34-48. https://doi.org/10.1093/toxsci/kfh121.

21. Boya P, Kroemer G. Lysosomal membrane permeabilization in cell death. Oncogene. 2008;27(50):6434-51. https://doi. org/10.1038/onc.2008.310.

22. Deng D, Jiang N, Hao SJ, Sun H, Zhang GJ. Loss of membrane cholesterol influences lysosomal permeability to potassium ions and protons. Biochimica et Biophysica Acta. 2009;1788(2):470-6. https://doi.org/10.1016/j.bbamem.2008.11.018.

23. Schroder K, Tschopp J. The inflammasomes. Cell. 2010;140(6):821-32. https://doi.org/10.1016/j.cell.2010.01.040.

24. Hiscott J, Marois J, Garoufalis J, D'Addario M, Roulston A, Kwan I, et al. Characterization of a functional NF-kappa B site in the human interleukin 1 beta promoter: evidence for a positive autoregulatory loop. Mol Cell Biol. 1993;13(10):6231-40.

25. Fujisawa A, Kambe N, Saito M, Nishikomori R, Tanizaki H, Kanazawa N, et al. Disease-associated mutations in CIAS1 induce cathepsin B-dependent rapid cell death of human THP-1 monocytic cells. Blood. 2007;109(7):2903-11. https://doi.org/10.1182/ blood-2006-07-033597.

26. Lin SJ, Yen HT, Chen YH, Ku HH, Lin FY, Chen YL. Expression of interleukin-1 beta and interleukin-1 receptor antagonist in oxLDL-treated human aortic smooth muscle cells and in the neointima of cholesterol-fed endothelia-denuded rabbits. J Cell Biochem. 2003;88(4):836-47. https://doi.org/10.1002/jcb.10431.

27. Endemann G, Stanton LW, Madden KS, Bryant CM, White RT, Protter AA. CD36 is a receptor for oxidized low density lipoprotein. J Biol Chem. 1993;268(16):11811-6.

28. Liu W, Yin Y, Zhou Z, He M, Dai Y. OxLDL-induced IL-1 beta secretion promoting foam cells formation was mainly via CD36 mediated ROS production leading to NLRP3 inflammasome activation. Inflamm Res Off J Eur Histamine Res Soc [et al]. 2014;63(1):33-43. https://doi.org/10.1007/s00011-013-0667-3.

29. Aits S, Jaattela M. Lysosomal cell death at a glance. J Cell Sci. 2013;126(Pt 9):1905-12. https://doi.org/10.1242/jcs.091181.

30. Rectenwald JE, Moldawer LL, Huber TS, Seeger JM, Ozaki CK. Direct evidence for cytokine involvement in neointimal hyperplasia. Circulation. 2000;102(14):1697-702.

31. Mehrhof FB, Schmidt-Ullrich R, Dietz R, Scheidereit C. Regulation of vascular smooth muscle cell proliferation: role of NFkappaB revisited. Circ Res. 2005;96(9):958-64. https://doi. org/10.1161/01.res.0000166924.31219.49.

32. Piva R, Belardo G, Santoro MG. NF-kappaB: a stress-regulated switch for cell survival. Antioxid Redox Signal. 2006;8(3-4):47886. https://doi.org/10.1089/ars.2006.8.478.

33. Zhang Q, Lenardo MJ, Baltimore D. 30 years of NF-kappaB: a blossoming of relevance to human pathobiology. Cell. 2017;168(1-2):37-57. https://doi.org/10.1016/j.cell.2016.12.012.

34. de Mingo A, de Gregorio E, Moles A, Tarrats N, Tutusaus A, Colell A, et al. Cysteine cathepsins control hepatic NF-kappaBdependent inflammation via sirtuin-1 regulation. Cell Death Dis. 2016;7(11):e2464. https://doi.org/10.1038/cddis.2016.368.

35. Orlowski GM, Colbert JD, Sharma S, Bogyo M, Robertson SA, Rock KL. Multiple cathepsins promote pro-IL-1beta synthesis and NLRP3-mediated IL-1beta activation. J Immunol. 2015;195(4):1685-97. https://doi.org/10.4049/jimmunol.15005 09.

36. Galea J, Armstrong J, Gadsdon P, Holden H, Francis SE, Holt CM. Interleukin-1 beta in coronary arteries of patients with ischemic heart disease. Arterioscler Thromb Vasc Biol. 1996;16(8):1000-6.

37. Moyer CF, Sajuthi D, Tulli H, Williams JK. Synthesis of IL-1 alpha and IL-1 beta by arterial cells in atherosclerosis. Am J Pathol. 1991;138(4):951-60. 